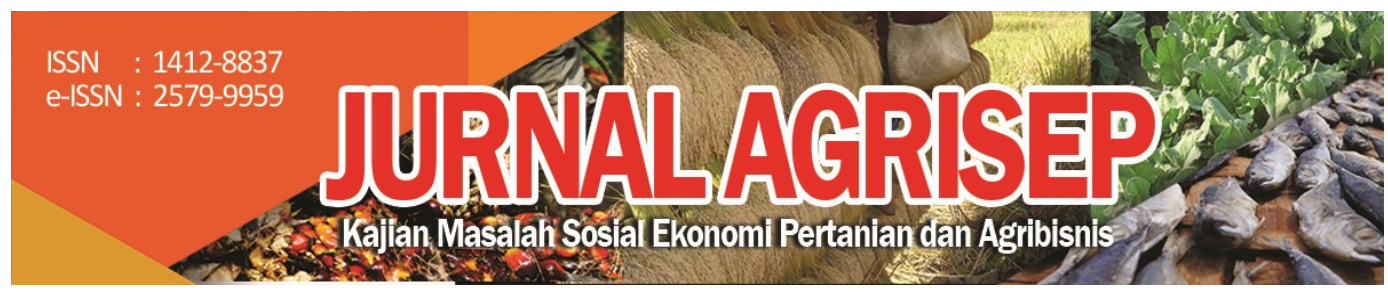

DOI: $10.31186 /$ jagrisep.20.2.227-238

\title{
INTERGRASI PASAR BERAS VERTIKAL ANTARA PETANI DAN PEDAGANG GROSIR DI INDONESIA
}

\section{Vertical Rice Market Integration Between Farmers and Wholesale Traders in Indonesia}

\author{
Muhlis $^{1} \bowtie$; Benny Osta Nababan ${ }^{2}$ \\ 1),2) Program Studi Manajemen, Sekolah Tinggi Ilmu Ekonomi Dewantara, Jawa \\ Barat, Indonesia \\ Email: mmuhlis2013@gmail.com
}

\begin{abstract}
This study aims to examine the vertical rice market integration between the rice market at the farmer level and the rice market at the wholesale trader level. This research uses monthly rice price for farmers and wholesaler from January 2013-July 2020 obtained from the Central Bureau of Statistic Indonesia. The results of the cointegration test indicate a long-term balance relationship between price changes at the farm level and prices at the wholesaler level. The estimation results of the vector error correction model show that the short-term balance relationship only occurs between changes in wholesale prices affected by changes in wholesale rice prices three months ago, premium rice prices at the farmer level three months ago and medium rice prices at the farmer level one month ago. The change in rice prices at the farmer level was only the premium rice price which was influenced by changes in the price of rice at the wholesale level three months ago.
\end{abstract}

Keywords : market integration, farmer, trader, rice

\section{ABSTRAK}

Penelitian ini bertujuan untuk menguji integrasi pasar beras vertikal antara pasar beras di tingkat petani dengan pasar beras di tingkat pedagang grosir. Data penelitian menggunakan data harga beras bulanan tingkat petani dan grosir dari bulan Januari 2013-Juli 2020 yang diperoleh dari Badan Pusat Statistik Indonesia. Pengujian kointegrasi terhadap model memperoleh hasil terdapat hubungan keseimbangan jangka panjang antara perubahaan harga di tingkat petani dengan harga di tingkat pedagang 
grosir. Hasil estimasi vektor error correction model menunjukkan bahwa hubungan keseimbangan jangka pendek hanya terjadi antara perubahan harga tingkat grosir dipengaruhi oleh perubahan harga beras grosir tiga bulan yang lalu, harga beras permium di tingkat petani tiga bulan yang lalu dan harga beras medium ditingkat petani satu bulan yang lalu. Perubahan harga beras ditingkat petani hanya harga beras premium yang dipengaruhi oleh perubahan harga beras di tingkat grosir tiga bulan yang lalu.

Kata kunci: integrasi pasar, petani, pedagang, beras

\section{PENDAHULUAN}

Beras adalah pangan pokok masyarakat Indonesia yang harus dijaga stabilitas harganya oleh pemerintah, karena terdapat dua sisi kepentingan yaitu petani sebagai produsen dan konsumen. Petani mengharapkan harga beras yang dapat memberikan penghidupan buat petani, disisi lain bagi konsumen mengharapkan harga beras yang dapat terjangkau. Selain itu, beras juga merupakan produk pertanian yang memiliki nilai elasitisas pengeluaran kurang dari satu (Yuliana et al, 2019), hal ini berarti beras termasuk kedalam barang yang tidak elastik. Nilai elastisitas pengeluaran dibawah satu berimplikasi terhadap tingkat sesitivitas rumah tangga terhadap perbahan pengeluaran total dan harga sendiri dalam konsumsi beras cukup rendah, sehingga apabila terjadi kenaikan harga beras akan berdampak terhadap berkurangnya alokasi sumberdaya rumah tangga buat non beras.

Dari sisi produksi, pasar beras di tingkat petani merupakan pasar monopsoni dimana jumlah petani lebih besar dari jumlah pedagang. Kondisi ini menyebabkan petani merupakan price taker, karena harga beras yang terbentuk di tingkat petani dilakukan oleh pedagang. Petani tidak memiliki kemampuan tawar yang kuat dalam bernegosisasi harga ditingkat petani, terutama untuk petani-petani yang memiliki luasan garap yang kecil. Makin sulitnya keadaan petani beras disebabkan oleh kenaikan harga input produksi seperti pupuk, bibit dan tenaga kerja mengakibatkan marjin keuntungan petani yang semakin berkurang. Selain hal-hal tersebut petani juga harus menanggung risiko terhadap ketidakpastian faktor alam yang tidak dapat diprediksi.

Kondisi yang dihadapi di sisi konsumen dan sisi produksi akan menyebabkan perubahan harga beras. Harga beras akan naik apabila terjadi kekurangan penawaran, hal sebaliknya harga beras akan turun bila terjadi kelebihan penawaran. Penawaran beras dapat dilakukan oleh petani dengan produksi padi dalam negeri dan pengadaan beras impor oleh pemerintah. Tidak terpenuhi kebutuahan dalam negeri dari produksi akan menyebabkan berkurangnya suplai dalam negeri serta menyebabkan kenaikan harga beras dalam negeri. Kondisi ini akan menguntungkan petani tetapi di sisi konsumen akan merugikan. Di kondisi seperti ini pemerintah harus memenuhi kekurangan 
beras dari produksi dalam negeri dengan cara mekanisme impor beras. Pada saat terjadi impor beras maka suplai beras dalam negeri akan meningkat yang diperoleh dari produksi ditambah impor, kondisi ini akan menyebabkan harga kembali turun yang menyebabkan kerugian bagi petani.

Perubahan harga beras terjadi pada setiap tingkatan pasar dimulai dari tingkat konsumen sampai tingkat pedagang akhir. Perubahan harga disatu pasar dapat mempengaruhi perubahan harga di pasar lainnya. Ukuran yang menunjukkan seberapa besar perubahaan harga yang terjadi di pasar acuan yang akan menyebabkan perubahan pada pasar berikutnya disebut Integrasi Pasar (Asmarantaka, 2009). Meyer dan Von Cramon-Taubadel (2004) menyebutkan indikator efisiensi untuk hubungan antara dua pasar yang saling berinteraksi secara spasial maupun vertikal adalah transmisi harga dan integrasi pasar. Tomek dan Robinson (1990) menyebutkan pasar terintegrasi secara effisien apabila pasar di wilayah yang berbeda memiliki hubungan harga yang positif. Dalam perdagangan menyebutkan tanpa adanya gesekan perdagangan (biaya transportasi), dalam kondisi pasar persaingan bebas serta fleksibilitas harga, barang yang sama bila dijual di lokasi yang berbeda harus dijual dengan harga yang sama, bila harga dinyatakan dalam mata uang umum (Law of one price). (Mankiw 2011; Zunaedah et al. 2015; Gluschenko 2018). Crucini et al. (2010) menambahkan biaya transportasi merupakan pembeda harga dari produk yang sama yang dijual dengan harga yang relatif sama dipasar yang berbeda. Integrasi pasar terdiri dari integrasi pasar spasial adalah integrasi pasar yang terpisah secara geografis dan integrasi pasar vertikal adalah integrasi pasar yang terjadi karena perbedaan tingkat pemasaran.

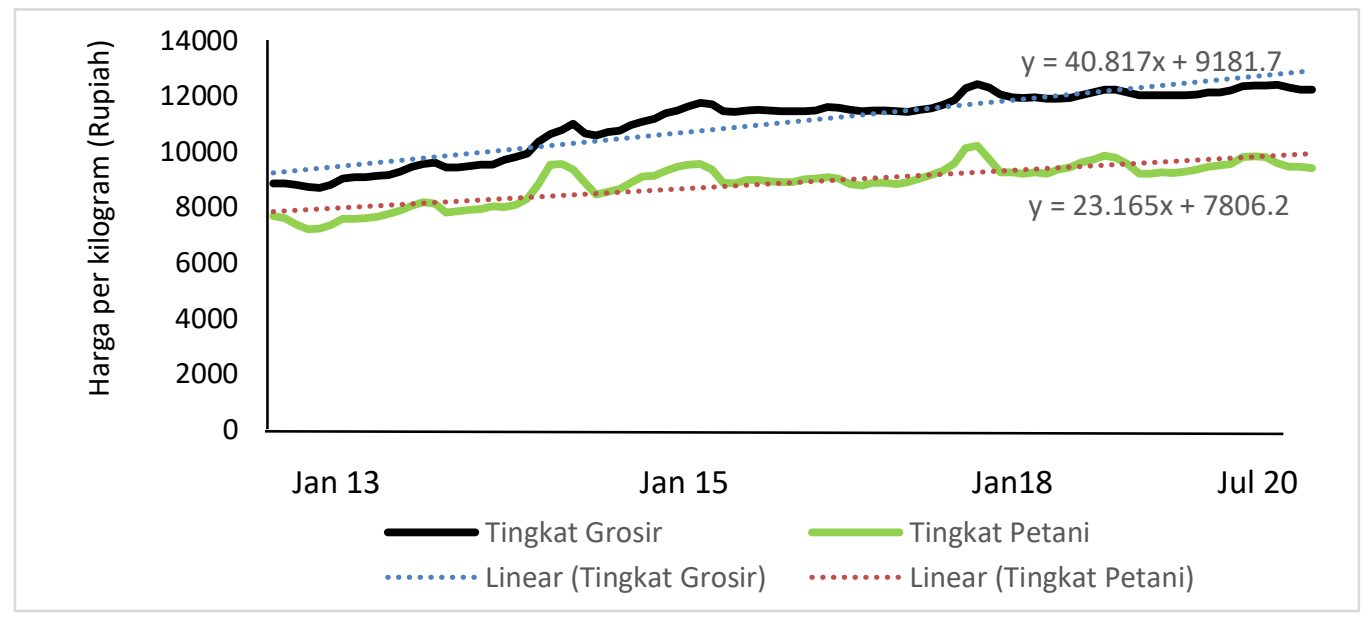

Sumber: BPS, 2020

Gambar 1.

Harga Beras Rata-rata di Petani dan Pedagang Grosir Periode Januari 2013-Juli 2020 
Gambar 1. menggambarkan perubahan harga beras ditingkat petani dan grosir di Indonesia dari bulan Januari 2013-Juli 2020. Dari dua pesamaan trend linier antara trend perubahan harga di tingkat petani dan tingkat grosir memiliki nilai parameter yang berbeda. Nilai parameter 40,817 ditingkat grosir dan 23,165 di tingkat petani. Perbedaan nilai ini menunjukan semakin bertambahnya waktu akan terjadi kesenjangan harga yang semakin tinggi antara kedua tingkat pasar tersebut. World Bank (2011) menyebutkan produsen akan mendorong peningkatan produksi apabila terjadi kenaikan harga, karena kenaikan harga merupakan suatu peluang yang harus diambil oleh produsen. Disisi lain peningkatan harga merupakan hal yang tidak diharapkan bagi konsumen karena akan menyebabkan daya beli menurun. Agar petani dapat menikmati perubahan harga yang terjadi ditingkat konsumen, maka harga di petani harus dapat terintegrasi dengan harga di konsumen. Sehingga dalam penelitian ini melihat integrasi harga ditingkat petani yang mewakili harga pasar beras tingkat petani dengan harga beras pedagang tingkat grosir yang dapat mewakili perilaku pedagang dalam menetapkan harga ke konsumen. Tujuan penelitian ini untuk mengetahui integrasi pasar beras vertikal di Indonesia. Tingkat pasar yang diuji adalah pasar beras di tingkat petani dengan pedagang grosir.

\section{METODE PENELITIAN}

Dalam penelitian ini data yang digunakan adalah data sekunder dengan jenis data time series bulan dengan periode Januari 2013- Juli 2019. Data diperoleh dari penelusuran situs resmi Badan Pusat Statistik Indonesia. Data yang dikumpulkan adalah harga beras rata-rata berdasarkan kualitas ditingkat petani dan pedangang grosir. Data yang digunakan dalam penelitian ini dapat dilihat pada Tabel 1.

Tabel 1. Data yang digunakan dalam penelitian

\begin{tabular}{clcc}
\hline No & \multicolumn{1}{c}{ Data } & Simbol & \multicolumn{1}{c}{ Satuan } \\
\hline 1 & $\begin{array}{l}\text { Harga beras rata-rata di tingkat pedagang } \\
\text { grosir }\end{array}$ & HBRG & Rupiah/kg \\
2 & $\begin{array}{l}\text { Harga beras kualitas premium di tingkat } \\
\text { petani (di penggilingan) }\end{array}$ & HBP & Rupiah/kg \\
3 & $\begin{array}{l}\text { Harga beras kualitas medium di tingkat } \\
\text { petani (di penggilingan) }\end{array}$ & HBM & Rupiah/kg \\
4 & $\begin{array}{l}\text { Harga beras kualitas lainya di tingkat petani } \\
\text { (di penggilingan) }\end{array}$ & HBKL & Rupiah/kg \\
\hline
\end{tabular}

Pendekatan model Johansen digunakan dalam penelitian ini untuk menganalisis integrasi vertikal pasar beras di Indonesia, dimana dengan model 
ini dapat melihat hubungan yang menggambarkan perubahan harga dipasar acuan yaitu pasar di grosir yang akan menyebabkan perubahan harga dipasar petani. Model integrasi pasar dalam penelitian ini dibuat dalam model pada pesamaan 1, pada Model 1 dapat dilihat interaksi harga antara HRBG, HBP, HBM dan HBKL. Model tersebut dapat dituliskan sebagai berikut:

$$
\Delta Y_{t}=\mu_{t}+\Pi Y_{t-1}+\Gamma_{1} \Delta Y_{t-1}+\cdots+\Gamma_{k} \Delta Y_{t-k}+e_{t}
$$

Di mana $\mu_{t}$ adalah vektor intersep, $\Pi$ adalah matrik koefisien jangka panjang $\left(\Pi=\mathrm{a} \beta^{\prime}\right)$, a adalah matrik loading, $\beta^{\prime}$ adalah vektor kointegrasi, $\Gamma$ adalah matrik koefisien penyesuaian jangka pendek ke jangka panjang, $Y$ adalah vektor variabel endogen (HRGB, HBP, HBM dan HBKL) dan $\varepsilon_{t}$ adalah error term.

Pengujian pertama adalah uji stationer Augmented Dickey-Fuller (ADF) untuk menentukan apakah data time series tidak mengandung unit root pada derajat yang sama sampai diperoleh data yang stationer. Pengujian ADF menggunakan model 2.

$$
\Delta Y_{t}=\alpha_{0}+\gamma Y_{t-1}+\sum_{i=1}^{p} \beta_{i} \Delta Y_{t-i}+\varepsilon_{t}
$$

Dimana $Y_{t}$ adalah variabel endogen harga beras (HRBG, HBP, HBM dan HBKL) pada periode $t, Y_{t-1}$ adalah variabel endogen harga beras periode sebelumnya, $Y_{t-i}$ adalah variabel endogen pada periode $t$ setelah dikurangi $\operatorname{lag}, \Delta Y_{t}$ adalah $Y_{t}-Y_{t-1}, p$ adalah jumlah lag pada model, $\alpha_{0}$ adalah intercept, $\gamma$ dan $\beta$ adalah koefisien parameter dan $\varepsilon_{t}$ error term. Kriteria pengambilan keputusan yang diharapkan adalah nilai prob kurang dari 0.05 maka data telah stasioner karena $Y_{t}$ tidak mengandung unit root.

Pengujian kedua adalah melakukan uji penentuan lag optimal dengan memanfaatkan informasi Akaike Information Criterion (AIC). Pengujian ini dilakukan untuk menghilangkan gejala autokorelasi yang terjadi pada model VAR. Dengan menggunakan lag optimal untuk mengetimasi model VAR diharapkan gejala autokorelasi tidak akan terjadi. Penentuan lag optimal berdasarkan nilai AIC yang diberi tanda bintang atau nilai terkecil.

Pengujian ketiga dengan mengestimasi model Johansen dengan metode pengujiian yang digunakan adalah trace test dan maximum eigenvalue test. Trace test untuk mengetahui vektor kointegrasi $\mathrm{r}$ (rank matrik $\Pi$ ) terbanyak, dengan mengikuti persamaan 3 , dimana $\mathrm{T}$ adalah jumlah observasi dan $\lambda_{\text {trace }}$ adalah eigenvalue. Metode Johansen dilakukan untuk mengetahui terdapat kointegrasi atau hubugan jangka panjang antara varibel endogen yang diuji.

$$
\lambda_{\text {trace }}=-T \sum \ln \left(1-\lambda_{i}\right)
$$

Sedangkan maximum eigenvalue test dilakukan dengan menguji relevansi $\mathrm{r}+1$ dalam $\beta\left(\Pi=\alpha \beta{ }^{\prime}\right)$ dengan persamaan 4 , dimana $\mathrm{r}$ adalah jumlah vektor kointegrasi pada hipotesis nol.

$$
\lambda_{\max }(r, r+1)=-T \sum \ln \left(1-\lambda_{r+1}\right)
$$


Kriteria pengambilan keputusan, jika nilai prob kedua nilai diatas kurang dari 0.05, maka antar variabel endogen dalam model terdapat hubungan jangka panjang.

Pengujian keempat dengan melakukan estimasi menggunakan vector error autoreggresion (VECM). VECM dipilih karena hasil uji kointegrasi terdapat terdapat persamaan kointegrasi dalam model. VECM digunakan untuk mengestimasi hubungan antar variabel endogen jangka panjang dan jangka pendek.

\section{HASIL DAN PEMBAHASAN}

Hasil uji ADF pada variabel penelitian menunjukan hasil pada tabel 2. Keseluruhan variabel yang diuji stasioner pada tidak stasioner pada level, sehingga keseluruhan data harus di uji pada first different. Hasil uji pada first different memperoleh prob kurang dari 0.05 , sehingga data dikatakan stasioner dan pengolahan data menggunakan data tersebut.

Tabel 2. Hasil uji ADF untuk variabel endogen

\begin{tabular}{lcc}
\hline \multicolumn{1}{c}{ Variabel } & Level & First different \\
\hline HRGB & 0.3938 & 0.0000 \\
HBP & 0.2304 & 0.0000 \\
HBM & 0.1698 & 0.0000 \\
HBKL & 0.0616 & 0.0000 \\
\hline
\end{tabular}

Pengujian panjang lag optimal yang digunakan dalam penelitian ini menggunakan kriteria AIC dengan melihat nilai yang paling kecil atau di beri tanda bintang. Uji AIC digunakan untuk menghilangkan gejala auto korelasi dalam model VAR yang digunakan. Hasil pengujian lag optimal pada penelitian ini menujukkan jumlah panjang lag optimal yang dapat digunakan dalam model adalah lag 4 yang dapat dilihat pada Tabel 3.

Tabel 3. Hasil pengujian panjang lag optimal

\begin{tabular}{cccllll}
\hline Lag & LogL & LR & FPE & AIC & SC & HQ \\
\hline 0 & -2362.650 & NA & $1.80 \mathrm{e}+19$ & 55.68588 & 55.80083 & 55.73212 \\
1 & -2021.266 & 642.6050 & $8.50 \mathrm{e}+15$ & 48.02979 & $48.60453^{* *}$ & 48.26097 \\
2 & -1990.824 & 54.43665 & $6.07 \mathrm{e}+15$ & 47.68999 & 48.72452 & $48.10611^{* *}$ \\
3 & -1975.854 & 25.36188 & $6.26 \mathrm{e}+15$ & 47.71421 & 49.20854 & 48.31527 \\
4 & -1956.754 & $30.55930^{* *}$ & $5.89 \mathrm{e}+15^{* *}$ & $47.64128^{* *}$ & 49.59540 & 48.42728 \\
5 & -1949.725 & 10.58519 & $7.42 \mathrm{e}+15$ & 47.85236 & 50.26627 & 48.82330 \\
6 & -1942.348 & 10.41404 & $9.36 \mathrm{e}+15$ & 48.05526 & 50.92897 & 49.21114 \\
\hline
\end{tabular}

232 | Muhlis dan Benny Osta Nababan; Integrasi Pasar Beras... 
Hasil uji johansen cointegration ditunjukkan pada Tabel 4. Hasil uji menggunakan trace dan Mac Kinnon pada model yang digunakan menunjukkan antara harga beras tingkat petani (premium, medium dan kualitas lainnya) dengan harga beras di grosir terjadi kointegrasi jangka panjang. Hasil yang diperoleh dari uji trace menunjukkan minimal terdapat tiga persamaan kointegrasi dalam model tersebut. Dapat dilihat pada tabel tersebut nilai prob dari hipotesis yang memiliki nilai dibawah 0.05 terdapat 3 persamaan yaitu $0.0009,0.0106$ dan 0.0465 .

Hasil pengujian eigenvalue diperoleh hasil yang menunjukkan terdapat 1 persamaan kointegrasi dengan nilai dibawah 0.05 terdapat 1 persamaan yaitu 0.0411. Hasil ini dapat diartika bahwa terdapat minimal satu persamaan kointegrasi dalam model tersebut. Dengan mengacu kepada kedua uji tersebut maka dalam model penelitian ini terdapat minimal tiga persamaan kointegrasi. Tiga persamaan kointegrasi yang terbentuk dari model tersebut adalah sebagai berikut:

$$
\begin{aligned}
& E C T 1=H R B G_{t-1}-1.9126 H B K L_{t-1}+5366.09 \\
& E C T 2=H B P_{t-1}-1.3392 H B K L_{t-1}+2345,42 \\
& E C T 3=H B M_{t-1}-1.1398 H B K L_{t-1}+905.94
\end{aligned}
$$

Persamaan kointegrasi yang terbentuk dari model ini berdasarkan dari estimasi VECM pada tabel 5.

Tabel 4. Hasil pengujian johansen cointegration

\begin{tabular}{lcccc}
\hline \multicolumn{1}{c}{ Hipotesis $\mathrm{r}$} & Eigenvalue & $\begin{array}{c}\text { Prob } \\
(\mathrm{a}=0.05)\end{array}$ & $\begin{array}{c}\text { Trace } \\
\text { Statistic }\end{array}$ & $\begin{array}{c}\text { Prob } \\
(\mathrm{a}=0.05)\end{array}$ \\
\hline Tidak ada & 0.279962 & $0.0411^{*}$ & 63.50164 & $0.0009^{*}$ \\
1 persamaan & 0.203351 & 0.0820 & 35.25483 & $0.0106^{*}$ \\
2 persamaan & 0.141537 & 0.0751 & 15.70345 & $0.0465^{*}$ \\
3 persamaan & 0.029541 & 0.1083 & 2.578845 & 0.1083 \\
\hline
\end{tabular}

Model penelitian diestimasi menggunakan vector error corection model (VECM). VECM memberikan informasi kecepatan penyesuaian menuju keseimbangan dari jangka pendek ke jangka panjang yang ditunjukkan oleh nilai error correction term (ECT). Berdasarkan Tabel 6 menunjukkan nilai koefisen ECT pada harga beras grosir sebesar 0.2711 dengan taraf signifikan 0.05 dan pada harga beras kualitas medium sebesar 0.3840 dengan taraf signifikan 0.10 . Nilai 0.2711 pada harga di pedagng beras grosir menunjukkan terdapat penyesuaian jangka pendek menuju kesimbangan jangka panjang sebesar 0.2711 atau terdapat koreksi kesalahan sebesar 0,2711 menuju keseimbangan jangka panjang. Nilai 0.3840 pada harga beras medium menunjukan terdapat koreksi kesalahan sebesar 0.3840 menuju keseimbangan jangka panjang. 
Pada jangka pendek perubahan harga beras grosir dipengaruhi oleh ECT2, perubahan harga beras di pedagang grosir itu sendiri pada lag 3 (tiga bulan yang sebelumnya), perubahan harga beras premium di petani tiga bulan sebelumnya dan perubahan harga beras medium di petani satu bulan sebelumnya. Nilai koefisien variabel perubahan harga beras dipedagang grosir tiga bulan sebelumnya sebesar 0.4297 dengan taraf signifikan 0.05 mempunyai arti bahawa setiap terjadi peningkatan harga beras dipedagang grosir sebesar satu persen pada tiga bulan yang lalu akan terjadi peningkatkan harga beras grosir 0.4297 persen pada taraf 0.05 . Nilai koefisien variabel perubahan harga beras premium tingkat petani tiga bulan sebelumnya sebesar -0.4209 pada taraf signifikan 0.05 mempunyai arti bahwa setiap terjadi penigkatan harga beras premium di petani sebesar satu persen tiga bulan yang lalu, maka harga beras dipedagang grosir terjadi penurunan sebesar 0.4209 persen pada tingkat signifikan 0.05 persen. Nilai koefisien variabel perubahan harga beras medium di petani sebulan yang lalu sebesar 0.3036 dengan taraf signifikan 0.10 mempunyai arti bahwa setiap terjadi peningkatan harga beras medium di petani sebulan yang lalu sebesar satu persen maka akan terjadi peningkatan harga beras di pedagang grosir sebesar 0.3036 persen

Dalam Tabel 5 dapat dilihat dalam jangka pendek perubahan harga beras grosir tiga bulan sebelumnya selain mempengaruhi perubahan harga grosir saat ini juga mempengaruhi perubahan harga beras premium di petani pada taraf signifikan 0.05. Perubahaan harga beras premium di petani tiga bulan sebelumnya selain mempengaruhi perubahan harga beras dipedagang grosir juga mempengaruhi harga beras medium dan kualitas lainnya dengan arah yang sama. Begitu juga dengan perubahan harga beras medium di petani satu bulan sebelumnya mempengaruhi perubahan harga beras premium dengan nilai 0.5575 pada taraf signifikan 0.10 dan mempengaruhi perubahan harga beras medium itu sendiri dengan nilai 0.7976 pada taraf signifikan 0.05 serta harga beras kualitas lainnya dengan nilai 0.7233 pada taraf signifikan 0.05 .

Persamaan integrasi jangka pendek pada taraf signifikansi 0.05 yang terbentuk dalam penelitian ini adalah sebagai berikut:

$$
\begin{aligned}
\Delta H R B G_{t}= & 0.2711\left(H B P_{t-1}-1.3392 H B K L_{t-1}+2345,42\right) \\
& +0.4297 H R B G_{t-3}-0.4209 H B P_{t-3}+44.0472+\varepsilon \\
\Delta H B P_{t}= & -0.5379 H B P_{t-3}+0.8034 H R B G_{t-3}+3.0278+\varepsilon \\
\Delta H B M_{t}= & 0.7976 H B M_{t-1}-0.6946 H B P_{t-3}+9.0590+\varepsilon \\
\Delta H B K L_{t}= & -0.7237 H B P_{t-3}+0.7233 H B M_{t-1}-7.2999+\varepsilon
\end{aligned}
$$

Persamaan integrasi jangka pendek yang terbentuk dari model ini berdasarkan dari estimasi VECM pada tabel 5. 
Tabel 5. Hasil estimasi VECM

\begin{tabular}{|c|c|c|c|c|}
\hline Cointegrating Eq: & ECT1 & ECT2 & ECT3 & \\
\hline HRBG(-1) & 1.000000 & 0.000000 & 0.000000 & \\
\hline $\operatorname{HBP}(-1)$ & 0.000000 & 1.000000 & 0.000000 & \\
\hline $\operatorname{HBM}(-1)$ & 0.000000 & 0.000000 & 1.000000 & \\
\hline HBKL(-1) & -1.912550 & -1.339197 & -1.139829 & \\
\hline $\mathrm{C}$ & 5366.090 & 2345.417 & 905.9442 & \\
\hline Error Correction: & $\mathrm{D}(\mathrm{HRBG})$ & $\mathrm{D}(\mathrm{HBP})$ & $\mathrm{D}(\mathrm{HBM})$ & $\mathrm{D}(\mathrm{HBKL})$ \\
\hline ECT1 & -0.102904 & 0.167919 & 0.089310 & 0.179427 \\
\hline ECT2 & $0.271129^{* *}$ & -0.038264 & $0.383978^{*}$ & 0.178629 \\
\hline ECT3 & -0.118275 & -0.076082 & -0.679220 & -0.289365 \\
\hline $\mathrm{D}(\mathrm{HRBG}(-1))$ & 0.035334 & 0.148621 & 0.237908 & 0.590169 \\
\hline $\mathrm{D}(\mathrm{HRBG}(-2))$ & -0.216383 & -0.290091 & -0.255324 & 0.054765 \\
\hline $\mathrm{D}(\mathrm{HRBG}(-3))$ & $0.429721^{* *}$ & $0.803385^{* *}$ & 0.493589 & 0.467281 \\
\hline $\mathrm{D}(\mathrm{HRBG}(-4))$ & -0.308066 & -0.058767 & -0.184649 & -0.167345 \\
\hline $\mathrm{D}(\mathrm{HBP}(-1))$ & -0.070149 & -0.106767 & -0.222813 & -0.202284 \\
\hline $\mathrm{D}(\mathrm{HBP}(-2))$ & -0.281988 & -0.432042 & -0.523279 & -0.660672 \\
\hline $\mathrm{D}(\mathrm{HBP}(-3))$ & $-0.420900^{* *}$ & $-0.537942^{* *}$ & $-0.694603^{* *}$ & $-0.723720^{* *}$ \\
\hline $\mathrm{D}(\mathrm{HBP}(-4))$ & -0.109192 & -0.108788 & -0.132497 & -0.176983 \\
\hline $\mathrm{D}(\mathrm{HBM}(-1))$ & $0.303572^{*}$ & $0.557497^{*}$ & $0.797636^{* *}$ & $0.723288^{* *}$ \\
\hline $\mathrm{D}(\mathrm{HBM}(-2))$ & 0.097778 & 0.130614 & 0.273907 & 0.241605 \\
\hline $\mathrm{D}(\mathrm{HBM}(-3))$ & 0.157882 & 0.111100 & 0.469245 & 0.261740 \\
\hline $\mathrm{D}(\mathrm{HBM}(-4))$ & 0.134930 & 0.248756 & 0.259846 & 0.310743 \\
\hline $\mathrm{D}(\mathrm{HBKL}(-1))$ & 0.067663 & 0.193109 & 0.043925 & -0.044748 \\
\hline $\mathrm{D}(\mathrm{HBKL}(-2))$ & 0.161921 & 0.174025 & 0.072883 & 0.190117 \\
\hline $\mathrm{D}(\mathrm{HBKL}(-3))$ & -0.055877 & 0.033185 & -0.041675 & 0.027771 \\
\hline $\mathrm{D}(\mathrm{HBKL}(-4))$ & 0.068902 & -0.170603 & -0.052947 & -0.080325 \\
\hline C & 44.04720 & 3.027766 & 9.058986 & -7.299903 \\
\hline R-squared & 0.590940 & 0.546710 & 0.569672 & 0.579089 \\
\hline F-statistic & 5.018188 & 4.189579 & 4.598495 & 4.779094 \\
\hline
\end{tabular}

** taraf signifikan $0.05 ;$ * taraf signifikan 0.10

Tabel 5 menunjukkan perubahan harga di tingkat petani untuk kualitas beras medium dan beras kualitas lainnya tidak dipengaruhi oleh perubahaan harga beras dipedagang grosir. Perubahaan harga dipedagang grosir hanya mempengaruhi harga beras di petani untuk kualitas premium. Kondisi ini akan menyebabkan terjadinya peningkatan harga beras di grosir tidak dapat dinikmati oleh petani yang memproduksi beras kualitas medium dan kualitas lainnya.

Penelitian-penelitian yang telah dilakukan mengenai integrasi pasar vertikal menyebutkan bahwa pasar beras ritel di Indonesia terintegrasi secara 
vertikal dengan pasar produsen Indonesia dalam jangka pendek dan jangka panjang (Kusumaningsih, 2015). Aryani (2012) menyebutkan pasar ritel beras Indonesia secara penuh belum berpadu dengan pasar produsen, pada jangka pendek harga beras ritel mempengaruhi harga gabah di produsen. Irawan dan Rosmayani (2007) menyebutkan di pasar Bengkulu Utara harga beras tingkat konsumen mempengaruhi harga beras tingkat grosir. Haryani dan Mulyaqin (2013) meyebutkan di Provinsi Banten antara petani dengan pedagan pengepul tingkat provinsi tidak terjadi integrasi harga. Saragih dan Rifin (2017) menyebutkan bahwa harga tingkat petani dapat mempengaruhi harga tingkat pedagang namun hal tersebut tidak belaku kebalikannya. Melihat dari penelitian sebelumnya dan penelitian yang telah dilakukan, integrasi pasar vertikal telah terintegrasi antara tingkatan-tingkatan pasar beras meskipun ada yang belum terintegrasi secara penuh.

Tidak terintegrasi secara penuh antar tingkat pasar pada rantai pemasaran beras di Indonesia terutama pada penelitian ini yang menunjukkan bahwa lemahnya posisi tawar yang dimilik oleh petani dalam menetapkan harga. Kenaikan harga beras yang terjadi di tingkat pedagang grosir dan konsumen tidak dapat dinikmati oleh petani hanya dinikmati oleh para pedagang. Kondisi ini terjadi karena pasar yang terbentuk di tingkat petani merupakan pasar monopsoni dimana jumlah petani lebih banyak dari pada pedagang, sehingga pedagang lebih memiliki kekuatan dalam menentukan harga. Hasil penelitian Lihan (2014) menyebutkan struktur pasar monopsoni pada beras menyebabkan petani hanya menikmati 33\% dari kenaikan harga yang terjadi, selebihnya dinikmati oleh pedagang. Dewi dan Saputra (2017) menyebutkan juga posisi petani yang merupakan penerima harga akan memperoleh bagian lebih kecil dibandingkan pedagang grosir dari perubahan harga yang terjadi.

Kebijakan pemerintah berupa Harga Pembelian Pemerintah sesuai dengan Permendag No. 24/2020 merupakan salah satu kebijakan perberasan untuk melindungi petani, dimana harga gabah kering panen di penggilingan $\mathrm{Rp}$

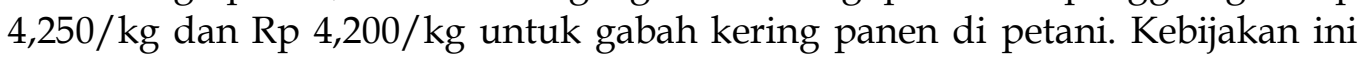
bertujuan untuk melindungi petani apabila terjadi penurunan harga yang tidak terkendali akibat dari gejolak harga di pasar beras. Berdasarkan Siswanto dan Sinaga (2018) menyebutkan simulasi peningkatan HPP dapat meningkatkan kesejahteraan petani. Hal ini sependepat dengan Nainggolan dan Soetjipto (2016) yang menyebutkan kebijakan pemerintah mengenai HPP beras mempengaruhi harga gabah dan berdampak terhadap kesejahteraan petani. Dengan adanya kebijakan ini pemerintah wajib menyerap beras dipasar apabila harga ada di bawah harga pembelian pemerintah. 


\section{SIMPULAN DAN SARAN}

\section{Simpulan}

Pengujian integrasi pasar beras vertikal di Indonesia antara petani dengan pedagang grosir menunjukkan adanya penyesuaian menuju keseimbangan baru dari jangka pendek ke jangka panjang untuk pasar beras medium di petani dan pasar beras di grosir. Perubahan harga beras yang terjadi di pedagang grosir dalam jangka pendek dipengaruhi oleh perubahan harga beras yang terjadi di pedagang grosir itu sendiri tiga bulan sebelumnya, perubahan harga beras permium di petani tiga bulan sebelumnya dan perubahan harga beras medium di petani satu bulan sebelumnya. Perubahan harga beras yang terjadi di pedaganggrosir tiga bulan sebelumnya hanya mempengarui perubahan harga beras premium di petani.

\section{Saran}

Pemerintah dalam menetapkan kebijakan stabilitas harga beras harus lebih memperhatikan petani-petani yang memproduksi beras dengan kualitas menegah dan lainya, karena melihat hasil penelitian yang telah dilakukan menunjukan bahwa perubahan harga beras di grosir tidak dapat dinikmati oleh petani beras menengah dan lainnya. Dalam pengendalihan harga beras, pemerintah harus menjaga stabilitas harga beras kualitas premium, karena perubahan harga beras premium akan mempengaruhi perubahan ke semua harga beras.

\section{DAFTAR PUSTAKA}

Aryani, D. 2012. Integrasi Vertikal Pasar Produsen Gabah dengan Pasar Ritel Beras di Indonesia. Jurnal Manajemen Teknologi. 11(2): 225-238

Asmarantaka, R. W. 2009. Pemasaran Produk-Produk Pertanian. Bunga Rampai Agribisnis: Seri Pemasaran. Bogor: IPB Press

Badan Pusat Statistik Republik Indonesia. 2019. Statistical yearbook of Indonesia 2019. Jakarta: Badan Pusat Statistika

Badan Pusat Statistik Republik Indonesia. 2020. Rata-rata Harga Beras di Tingkat Pedagang Besar/Grosir Indonesia. (diakses 25 Agustus 2020). https://www.bps.go.id/linkTableDinamis/view/id/963

Badan Pusat Statistik Republik Indonesia. 2020. Harga Beras di Penggilingan Menurut Kualitas. (diakses 25 Agustus 2020). https://www.bps.go.id/subject/36/hargaprodusen.html\#subjekView $\underline{\text { Tab5. }}$.

Dewi, N. dan Saputra, A. J. 2017. Analisis Struktur Perilaku dan Kinerja Pasar (Stucture, Conduct and Market Performan) Komoditi Padi Di Desa Bunga 
Raya dan Desa Kemuning Muda Kecamatan Bunga Raya Siak. Indonesia Journal of Agricultural Economics (IJAE). 19(1): 42-56

Crucini, M. J., Shintani, M., dan Tsuruga, T. 2010. The Law of One Price Without the Border: the Role of Distance Versus Sticky Price. The Economic Journal. 120: 462-480

Gluschenko, K. 2018. Spatial Integration of Siberian Regional Markets. Munich Personal RePEc Archive Paper No. 85667

Haryani, D. dan Mulyaqin, T. 2013. Kajian Analisis Margin Pemasaran dan Integrasi Pasar Gabah/Beras di Provinsi Banten. Buletin Ikatan. 3(1): 5669

Irawan, A. dan Romayanti, D. 2007. Analisis Integrasi Pasar Beras di Bengkulu. Jurnal Agro Ekonomi. 25(1): 37-54

Kusumaningsih, A. 2015. Analisis Integrasi Pasar Beras di Indonesia. Buletin Bisnis dan Manajemen. 1(2): 130-141

Lihan Irham. 2014. Kajian Struktur Pasar Gabah dan Beras di Indonesia. Jurnal Neo-Bis. 8(1): 63-76

Mankiw, N. G. 2011. Principles of Economics (6 th $^{\text {th }}$ d). Mason (OH): South-Western Cengage Learning

Meyer, J. dan Von, C. S. 2004. Asymmetric price transmission: survey. Journal of Agricultural Economics. 55(3): 581-611

Nainggolan, L. B. dan Soetjipto, W. Analisis Efektivitas Kebijakan Harga Pembeliah Pemerintah (HPP) Beras. Jurnal Kebijakan Ekonomi. 11(2): 126142

Peraturan Menteri Perdagangan Nomor 24 Tahun 2020 tentang Penetapan Harga Pembelian Pemerintah (HPP) Untuk Gabah Atau Beras. 16 Maret 2020

Saragih, A. E. dan Rifin, N. T. A. 2017. Rantai Pasok Produk Beras di Kecamatan Cibeber Kabupaten Cianjur. Jurnal Manajemen \& Agribisnis. 14(3): 218228

Siswanto, E. dan Sinaga, B. M. 2018. Dampak Kebijakan Perberasan Pada Pasar Beras dan Kesejahteraan Produsen dan Konsumen Beras di Indonesia. Jurnal Ilmu Pertanian Indonesia. 23(2): 93-100

Tomek, W. G. dan Robinson, K. L. 1990. Agricultur Product Prices. 2nd edition. Ithaca and London: Cornell University Press

World Bank. 2011. Perkembangan, Pemicu Dan Dampak Harga Komoditas: Implikasinya Terhadap Perekonomian Indonesia. Laporan Perkembangan Sektor Perdagangan. World Bank. Jakarta. Maret 2011

Yuliana, R., et al. 2019. Dampak Perubahan Harga Pangan Terhadap Tingkat Kesejahteraan Rumah Tangga di Indonesia. Jurnal Agro Ekonomi. 37(1): $25-45$

Zunaidah, A. D., Setiawan, B. dan Anindita, R. 2015. Analisis Integrasi Pasar Apel. Jurnal Habitat. 26(3): 183-194 